\title{
Clinicopathological Significance of Autophagy-related Proteins and its Association With Genetic Alterations in Gliomas
}

\author{
SAMANTHA TAMRAKAR ${ }^{1}$, MASAKAZU YASHIRO ${ }^{2,3}$, TOSHIYUKI KAWASHIMA ${ }^{1}$, TAKEHIRO UDA ${ }^{1}$, \\ YUZO TERAKAWA ${ }^{1}$, YUKO KUWAE ${ }^{4}$, MASAHIKO OHSAWA ${ }^{4}$ and KENJI OHATA ${ }^{1}$ \\ ${ }^{1}$ Department of Neurosurgery, Osaka City University Graduate School of Medicine, Osaka, Japan; \\ ${ }^{2}$ Department of Surgical Oncology, Osaka City University Graduate School of Medicine, Osaka, Japan; \\ ${ }^{3}$ Molecular Oncology and Therapeutics, Osaka City University Graduate School of Medicine, Osaka, Japan; \\ ${ }^{4}$ Department of Diagnostic Pathology and Molecular Pathology, \\ Osaka City University Graduate School of Medicine, Osaka, Japan
}

\begin{abstract}
Aim: To investigate clinicopathological significance of autophagy and its association with genetic alterations in gliomas. Materials and Methods: The expression of three autophagy-related proteins, light chain-3 (LC3), beclin 1, and p62 was immunohistochemically analyzed in 32 low-grade gliomas and 65 high-grade gliomas. Results: LC3, beclin 1, and p62 expression was positive in 70/94 (74\%), 51/94 (54\%) and 55/96 (57\%) gliomas, respectively. High expression of LC3, beclin 1 and p62 was significantly more frequent in high-grade gliomas than in low-grade. Positive expression of LC3, beclin 1 and p62 were significantly positively correlated with overall survival, methylation of $O^{6}$-methylyguanine-DNA methyltransferase (MGMT) promoter, mutations of isocitrate dehydrogenase 1 (IDH1) and telomerase reverse transcriptase (TERT) promoter, and $1 p / 19 q$ co-deletion. Kaplan-Meier analyses revealed that LC3, p62 and autophagy status (positivity for at least two of the three proteins) were significantly associated with poorer survival. Conclusion: Autophagy might be associated with the progression of glioma, particularly high-grade, and thus might be a useful prognostic factor in patients with glioma.
\end{abstract}

Glioma accounts for nearly $80 \%$ of all brain tumors and arises from glial cells of the brain cells (1). Based on their aggressiveness, they can be classified as low-grade gliomas (LGG) or high-grade gliomas (HGG) (2). LGG can progress into malignant tumor of World Health Organization (WHO)

Correspondence to: Masakazu Yashiro M.D., Molecular Oncology and Therapeutics, Osaka City University Graduate School of Medicine, 14-3 Asahimachi, Abeno-ku, Osaka 545-8585, Japan. Tel: +81 666453838, Fax: +81 666466450, e-mail: m9312510@med.osakacu.ac.jp ORCHID: 0000-0001-5743-7228

Key Words: Glioma, autophagy, LC3, beclin 1, p62, genetic alterations. grade III or IV, with an incidence of $23-72 \%$ and conferring a median survival time of 2.7-5.4 years (3-5). HGG, mainly glioblastoma (GBM), classified as grade IV by the WHO, is one of the most lethal forms of malignant gliomas, is highly infiltrative, and progresses rapidly $(2,6,7)$. Despite multimodal therapies including standard surgical resection followed by radiation and chemotherapy, HGG continues to confer a poor prognosis, with a median survival time of 9-12 months $(1,7)$. Therefore, uncovering the mechanism of tumorigenesis of glioma is crucial for discovering novel treatments to improve the prognosis of patients $(8,9)$. Furthermore, genetic mutations such as of $O^{6}$ methylyguanine-DNA methyltransferase (MGMT), isocitrate dehydrogenase 1 (IDHI), tumor protein 53 (TP53), telomerase reverse transcriptase (TERT) promoter, and $1 \mathrm{p} / 19 \mathrm{q}$ chromosomal co-deletion are essential molecular gene mutations for the final pathological diagnosis of gliomas (10).

Over the years, the role of autophagy in the pathogenesis of various cancer types has been widely recognized and considered as a vital target in cancer therapy $(8,11,12)$. Recent studies have shown autophagy to play dual functions in cancer: it can suppress the development of cancer in early stages by eliminating damaged proteins and organelles, or facilitate tumor growth in low oxygen and nutrient-deprived conditions $(9,13,14)$. Autophagy is a 'self-eating' catabolic process occurring in all eukaryotic cells in response to starvation in which cellular organelles (cargo), proteins and cytoplasm are engulfed, digested and recycled to sustain cellular metabolism $(15,16)$. These recycled intracellular constituents also serve as an alternative source of energy during stress conditions (16). In most cells, autophagy usually occurs at low levels, but can be up-regulated in stress conditions such as starvation, hypoxia, infection or nutrient deprivation $(11,17)$. There are three types of autophagy based on how the cellular constituents are delivered to the lysosome: Microautophagy, chaperone-mediated autophagy 
(CMA) and macroautophagy $(8,18)$. Microautophagy is a non-selective process which involves the direct engulfment of the cytoplasm at the lysosomal surface by invagination, protrusion or septation of the lysosomal limiting membrane $(16,19)$. CMA is a selective process which delivers soluble proteins recognized by molecular chaperones to the lysosome (8). In contrast, in macroautophagy (hereafter referred to as autophagy), portions of cellular organelles, proteins and cytoplasm are engulfed, digested and recycled to sustain cellular metabolism via a double-membrane vesicle termed an autophagosome (19). Subsequently, autophagosomes bind with lysosomes to degrade and recycle their content (20).

The process of autophagy is regulated by a series of autophagy-related genes (ATGs) (21). For the formation of autophagosome and cargo recruitment, two ubiquitin-like conjugation systems, namely ATG12-ATG5-ATG16 and ATG8 conjugation system are crucial (22). Microtubule-associated protein 1 light chain 3 (LC3) belongs to the ATG8 protein family and is a structural component of autophagosomes (7, 23). Various studies have shown autophagy to be highly selective [reviewed in (18)]. This selectivity is ascribed to autophagy receptors that are able to interact with the autophagy machinery and on the other hand recognize a ligand-bound cargo (24). One of the most studied autophagy receptors is p62, which is involved in autophagic degradation (20). Beclin 1 is a tumor-suppressor gene and is an autophagosome initiation protein $(7,25)$ : Studies have revealed LC3, beclin 1 and p62 to be essential markers for autophagy (25-28).

There are studies that have reported high expression of different autophagy-related proteins in various cancer cells (29-31). For this reason, using a single autophagy-related protein marker alone to determine the autophagy status might be unreliable. Therefore, we included the study of three autophagy-related proteins, LC3, beclin 1 and p62 to determine the autophagy status and evaluate their expression in different forms of glioma.

In the present study, the expression of the autophagy-related proteins, LC3, beclin 1, and p62, in glioma specimens were evaluated, and the correlation between clinicopathological features and autophagy in glioma was investigated. Additionally, the correlation between genetic alterations in glioma and autophagy-related proteins was also investigated. The correlation between autophagy-related proteins with clinicopathological features along with genetic alterations of gliomas, are rare in the literature. To the best of our knowledge, this is the first study to investigate genetic features and autophagy-related proteins, LC3, beclin 1, and p62, in gliomas.

\section{Materials and Methods}

Clinical materials. A total of 97 patients who had undergone surgery for different grades of diffuse glioma from 2001 to 2017 at the Department of Neurosurgery, Osaka City University, were included in the study. Exclusion criteria included samples from biopsy, insufficient tumor sample or unavailable follow-up data. All specimens were histopathologically classified and revised genetically according to the World Health Organization (WHO 2016) of tumors of the central nervous system (1) by an expert neuropathologist. None of the patients received preoperative radiation or chemotherapy. All glioma tissues were obtained at the time of surgery. The tumors were further sub-grouped as LGG $(n=32)$ and HGG $(n=65)$, where the LGG group consisted of grade II and the HGG consisted of grade III and IV (Table I). Overall survival (OS) was defined as the time from diagnosis to death of the patient. This study was carried out in accordance with the principles of the Helsinki Declaration and was approved by the Osaka City University Ethics Committee (approval number: 3084 and 2047) and all collaborative institutes. Written informed consent was obtained from all patients.

Immunohistochemical techniques. Immunohistochemical determination of LC3, beclin 1 and p62 were examined as per the manufacturer's instructions. Immunohistochemical staining was performed on $4-\mu \mathrm{m}$ sections of formalin-fixed paraffin-embedded tissue using a Bond Polymer Refine Detection system (catalogue \#DS 9800; Leica Biosystems Newcastle Ltd, Newcastle upon Tyne, UK). Immunohistochemistry was performed using the following antibodies: anti-LC3 (ab48394, 1:1200; Abcam, Cambridge, UK), anti-beclin 1 (NB500-249, 1:100; Novus, Littleton, CO, USA) and anti-p62 (5F2, 1:400; MBL, Nagoya, Japan) on Leica BOND-MAX (Leica).

Assessment of immunohistochemical staining. Immunostaining was interpreted by two independent investigators who were blinded to the clinicopathological features of the patients. The cutoff values were decided by the cumulative mean value of the total score of all samples: Immunoreactivity of more than $30 \%$ of cancer cells was regarded as positivity for beclin 1 and p62, whereas immunoreactivity of more than $25 \%$ of cancer cells was regarded as positivity for LC3. Each sample was scored individually using the cumulative mean score of five $200 \times$ magnification fields. Autophagy status was considered positive when the sample was positive for at least two out of the three autophagy proteins.

Genetic analysis. Genetic analyses were conducted at two laboratories: Osaka National Hospital (ONH), Osaka, Japan and the National Cancer Center Research Institute (NCC), Tokyo, Japan. For all cases, tumor DNA was extracted from frozen tumor tissue using a DNeasy Blood \& Tissue kit (Qiagen, Tokyo, Japan). The methylation status of the MGMT promoter was analyzed and assessed by quantitative polymerase chain reaction (qPCR) at $\mathrm{ONH}$ or by pyrosequencing after bisulfite modification of genomic DNA at NCC. Hotspot mutations of IDHI/2 (codon 132 of IDHI and codon 172 of IDH2), TERT promoter (termed C228 and C250) and TP53 gene were analyzed by Sanger's sequencing and pyrosequencing at either lab. The copy number status of $1 p$ and $19 q$ were analyzed using multiplex ligation-dependent probe amplification in a unified workflow at either laboratory. Detailed information on genetic analysis, including PCR and sequencing of each gene, can be found in previous publication (32):

Statistical analysis. The chi-square test was used to compare the immunohistochemical findings with the clinicopathological features. The overall survival curves were estimated using the Kaplan-Meier method and log-rank test was used to compare the cumulative survival durations among each patient groups. Additionally, the Cox proportional hazards model was used to compute univariate and 
Table I. Summary of clinicopathological and molecular characteristics of 97 glioma cases.

\begin{tabular}{|c|c|}
\hline Clinicopathological feature & Value \\
\hline \multicolumn{2}{|l|}{ Gender } \\
\hline Female & 43 \\
\hline Male & 54 \\
\hline \multicolumn{2}{|l|}{ Age, years } \\
\hline Median (range) & $46(13-82)$ \\
\hline \multicolumn{2}{|l|}{ Histopathological type $(\mathrm{WHO} \text { grade })^{\mathrm{a}}$} \\
\hline II & 32 \\
\hline III & 22 \\
\hline IV & 43 \\
\hline \multicolumn{2}{|l|}{ Histopathological group } \\
\hline LGG & 32 \\
\hline HGG & 65 \\
\hline \multicolumn{2}{|l|}{ Status at 5 years } \\
\hline Dead & 24 \\
\hline Alive & 73 \\
\hline \multicolumn{2}{|l|}{ Recurrence } \\
\hline No recurrence & 56 \\
\hline Recurrence & 41 \\
\hline \multicolumn{2}{|l|}{2016 WHO classification, $\mathrm{n}$} \\
\hline \multicolumn{2}{|l|}{ Grade II } \\
\hline Diffuse astrocytoma, mutant $I D H$ & 19 \\
\hline Diffuse astrocytoma, wild-type $I D H$ & 5 \\
\hline Oligodendroglioma, mutant $I D H$ and $1 \mathrm{p} / 19 \mathrm{q}$ co-deletion & 6 \\
\hline Oligodendroglioma, NOS & 2 \\
\hline \multicolumn{2}{|l|}{ Grade III } \\
\hline Anaplastic astrocytoma, mutant $I D H$ & 6 \\
\hline Anaplastic astrocytoma, wild-type $I D H$ & 10 \\
\hline \multicolumn{2}{|l|}{ Anaplastic oligodendroglioma, mutant } \\
\hline$I D H$ and $1 \mathrm{p} / 19 \mathrm{q}$ co-deletion & 4 \\
\hline Anaplastic oligodendroglioma, NOS & 2 \\
\hline \multicolumn{2}{|l|}{ Grade IV } \\
\hline Glioblastoma, wild-type $I D H$ & 37 \\
\hline Glioblastoma, mutant $I D H$ & 6 \\
\hline \multicolumn{2}{|l|}{$M G M T$ promoter, n $(\%)$} \\
\hline Methylated & $61(62.8 \%)$ \\
\hline Unmethylated & $36(37.1 \%)$ \\
\hline \multicolumn{2}{|l|}{$I D H 1, \mathrm{n}(\%)$} \\
\hline Wild-type & $56(57.7 \%)$ \\
\hline Mutant & $41(42.2 \%)$ \\
\hline \multicolumn{2}{|l|}{ TP53, n (\%) } \\
\hline Mutation & $34 / 76(44.7 \%)$ \\
\hline \multicolumn{2}{|l|}{ TERT promoter, $\mathrm{n}(\%)$} \\
\hline Mutation & $38 / 90(42.2 \%)$ \\
\hline \multicolumn{2}{|l|}{$1 p / 19 q$ co-deletion } \\
\hline Yes & $11 / 52(21.1 \%)$ \\
\hline
\end{tabular}

aHistopathological type was classified genetically according to the 2016 World Health Organization of Tumors of the Central Nervous System (1). LGG: Low-grade glioma; HGG: high-grade glioma; IDH: isocitrate dehydrogenase; NOS: not otherwise specified; MGMT: $O^{6}$ methylyguanine-DNA methyltransferase; TP53: tumor protein 53; TERT: telomerase reverse transcriptase.

multivariate hazards ratios for the study parameters. For all of the tests, a $p$-value $<0.05$ was considered as being statistically significant. The SPSS software program (SPSS Japan, version 22, Tokyo, Japan) was used for the analyses.

\section{Results}

Correlation between clinicopathological features and autophagy. The expression of autophagy markers in resected specimens of LGG and HGG was evaluated by immunohistochemistry. A summary of the clinicopathological characteristics of the glioma cases are shown in Table I. Strong expression of LC3, beclin 1, and p62 were found in both the nucleus and cytoplasm of HGG compared with LGG cells (Figure 1). Among the 97 glioma cases, LC3, beclin 1, and p62 expression were positive in 70/94 (74\%), 51/94 (54\%) and 55/96 (57\%) cases respectively.

The relationship between expression of autophagy proteins and clinicopathological variables are shown in Table II. LC3, beclin 1 and $\mathrm{p} 62$ expression was significantly associated with HGG ( $p=0.004, p \leq 0.001$ and $p=0.006$ respectively); LC3 and p62 expression also significantly correlated with poorer overall survival ( $p=0.005$ and $p=0.020$, respectively). Autophagy status was defined as positive when two out of the three autophagy-associated proteins were expressed in each sample. Expression of LC3, beclin 1 and p62 and positive autophagy status was higher in samples from patients who received radiation post operatively $(p=0.029$, $p=0.002, p=0.001$ and $p=0.006$ respectively). Interestingly, positivity for LC3 $(\mathrm{n}=52,74.2 \%)$, beclin $1(\mathrm{n}=42,82.3 \%)$, p62 $(n=43,78.1 \%)$ and autophagy $(n=50,79.3 \%)$ was more prominent in HGG than in LGG. In most of the HGG cases, extensive staining of autophagy proteins was seen in both the nucleus as well as in the cytoplasm of the tumor cells. Out of the 97 cases, autophagy status was positive in 63 cases (64.9\%). Autophagy-positive status was also significantly associated with HGG $(p \leq 0.001)$, poorer overall survival $(p=0.023)$ and postoperative radiation $(p=0.006)$.

Correlation between autophagy markers and genetic alterations in gliomas. The relationship between the autophagy protein expression and genetic alterations are shown in Table II. There was strong association between LC3 expression and methylation of $M G M T$ promoter $(p=0.021)$ and mutation of TERT $(p=0.010)$ promoter; beclin 1 expression with $I D H I$ mutation $(p=0.003)$ and $1 \mathrm{p} / 19 \mathrm{q}$ codeletion ( $p=0.045$ ); p62 expression with $M G M T$ promoter methylation $(p=0.034)$, IDHI mutation $(p=0.022)$ and $1 \mathrm{p} / 19 \mathrm{q}$ co-deletion $(p=0.038)$. Statistically, there was a significant correlation between autophagy-positive status: and: MGMT methylation $(p=0.002)$, IDHI mutation $(p=0.004)$ and $1 \mathrm{p} / 19 \mathrm{q}$ co-deletion $(p=0.034)$. However, there was no correlation between autophagy status and TP53 and TERT mutation ( $p=0.254$ and $p=0.170)$.

Correlation among autophagy markers. There was significant positive correlation among the autophagy proteins LC3, beclin 1 and p62 ( $p$-value $=0.005,0.080$ and 0.001 respectively) (Table III). 

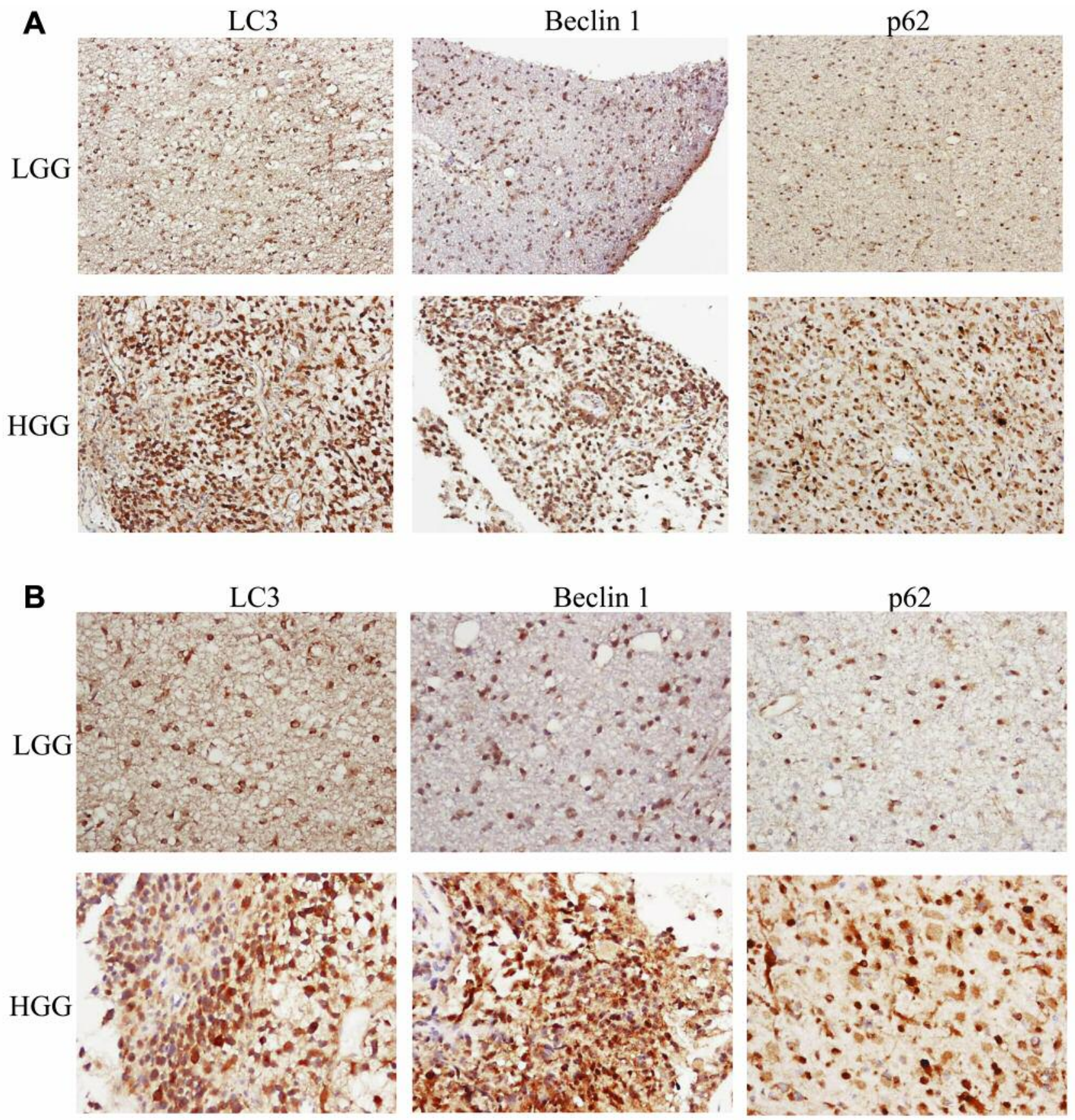

Figure 1. Representative immunohistochemistry staining of autophagy-related proteins light chain 3 (LC3), beclin 1 and p62, in low-grade (upper panels) and high-grade (lower panels) gliomas at low $(A ; \times 200)$ and high $(B ; \times 400)$ magnification. The expression level of autophagy-related proteins $L C 3$, beclin 1, and p62 was found to be weak in low-grade glioma (LGG), compared to high-grade glioma $(H G G)$.

Survival. Regional recurrences occurred in 41 out of 97 patients $(42.2 \%)$.

Evaluation of the association of autophagy proteins with overall survival was estimated using Kaplan-Meier survival analysis (Figure 2). The prognosis of patients with LC3positive, p62-positive and autophagy-positive status was significantly poorer $(p=0.007, p=0.012$ and $p=0.013$ respectively) than that of patients negative for the respective marker. The survival prognosis of beclin 1-positive cases was non-significant $(p=0.074)$. Univariate analyses revealed that overall survival was significantly poorer in those with LC3positive $(p=0.027), \mathrm{p} 62$-positive $(p=0.018)$, autophagy- 


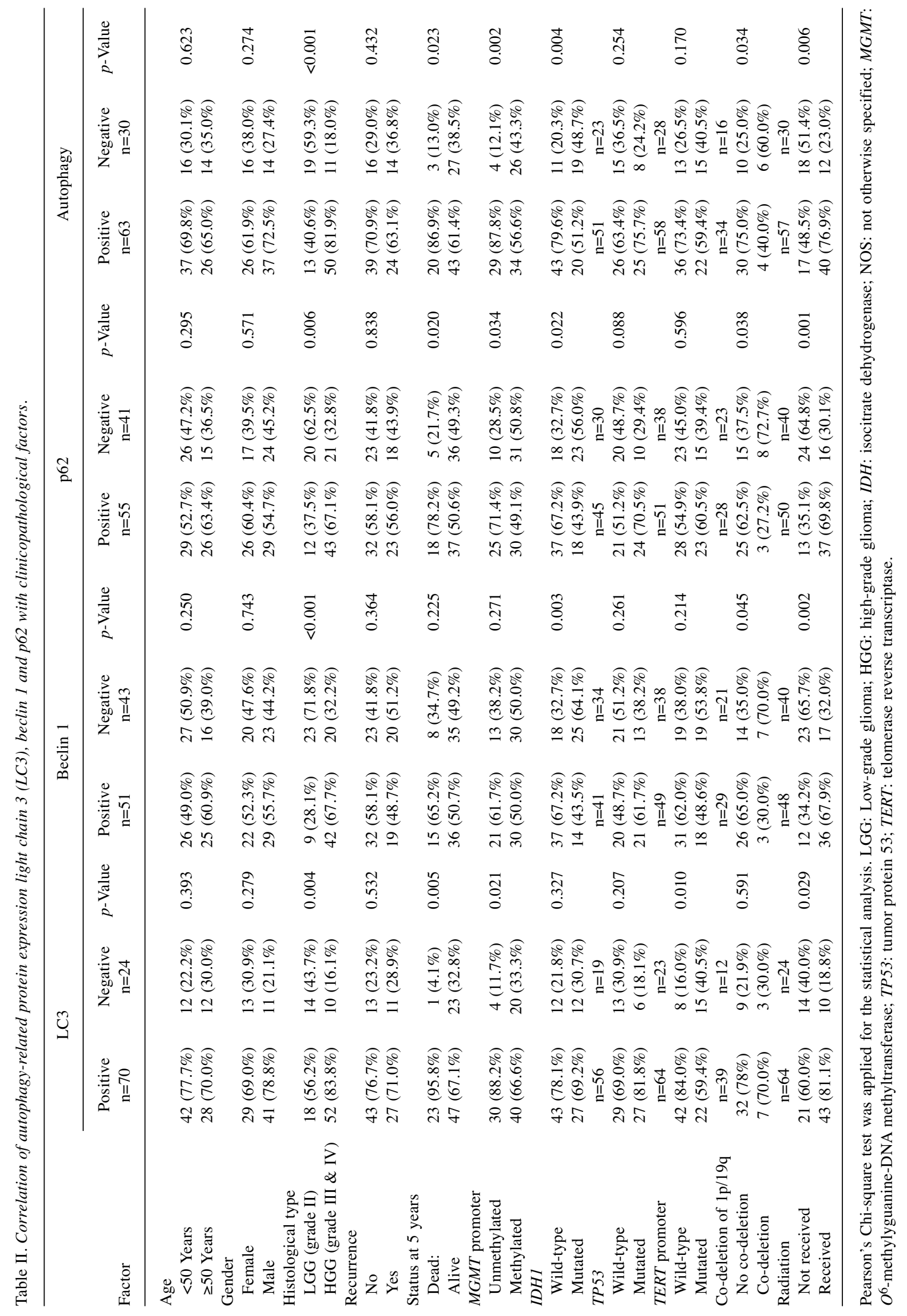


Table III. Association among autophagy-related proteins light chain 3 (LC3), beclin 1 and p62.

\begin{tabular}{|c|c|c|c|c|c|c|}
\hline \multirow[b]{2}{*}{ Factor } & \multicolumn{2}{|c|}{ Beclin 1} & \multirow[b]{2}{*}{$p$-Value } & \multicolumn{2}{|c|}{ p62 } & \multirow[b]{2}{*}{$p$-Value } \\
\hline & $\begin{array}{c}\text { Negative } \\
(\mathrm{n}=43)\end{array}$ & $\begin{array}{c}\text { Positive } \\
(\mathrm{n}=50)\end{array}$ & & $\begin{array}{c}\text { Negative } \\
(\mathrm{n}=38)\end{array}$ & $\begin{array}{c}\text { Positive } \\
(\mathrm{n}=55)\end{array}$ & \\
\hline \multicolumn{7}{|l|}{ LC3 } \\
\hline Negative $(n=24)$ & $17(70.8 \%)$ & $7(29.1 \%)$ & 0.005 & $17(70.8 \%)$ & $7(29.1 \%)$ & 0.001 \\
\hline Positive $(\mathrm{n}=69)$ & $26(37.6 \%)$ & $43(62.3 \%)$ & & $21(30.4 \%)$ & $48(69.5 \%)$ & \\
\hline Beclin 1 & & & & $(n=39)$ & $(n=55)$ & \\
\hline Negative $(n=43)$ & & & & $22(51.1 \%)$ & $21(48.8 \%)$ & 0.080 \\
\hline Positive $(n=51)$ & & & & $17(33.3 \%)$ & $34(66.6 \%)$ & \\
\hline
\end{tabular}

Pearson's Chi-square test was applied for the statistical analysis.

Table IV. Univariate and multivariate analyses with respect to overall survival of patients with glioma.

\begin{tabular}{|c|c|c|c|c|c|c|c|}
\hline \multirow[b]{2}{*}{ Variable } & & \multicolumn{3}{|c|}{ Univariate analysis } & \multicolumn{3}{|c|}{ Multivariate analysis } \\
\hline & & Hazard ratio & $95 \% \mathrm{CI}$ & $p$-Value & Hazard ratio & $95 \% \mathrm{CI}$ & $p$-Value \\
\hline LC3 & Positive $v s$. negative & 9.6 & $1.3-71.6$ & 0.027 & 9.731 & $0.6-138$ & 0.093 \\
\hline Beclin 1 & Positive $v s$. negative & 2.1 & $0.9-5.0$ & 0.081 & & & \\
\hline p62 & Positive $v s$. negative & 3.3 & $1.2-9.0$ & 0.018 & 1.417 & $0.3-6.2$ & 0.644 \\
\hline Autophagy & Positive $v s$. negative & 4.1 & $1.2-13.9$ & 0.022 & 0.258 & $0.02-2.3$ & 0.229 \\
\hline Age & $<50 v s . \geq 50$ Years & 2.1 & $0.9-4.8$ & 0.060 & & & \\
\hline Gender & Female $v s$. male & 0.6 & $0.2-1.5$ & 0.344 & & & \\
\hline Tumor recurrence & Positive $v s$. negative & 0.7 & $0.3-1.7$ & 0.552 & & & \\
\hline Histological type & High-grade $v s$. low-grade & 18.9 & $2.5-141.2$ & 0.004 & 1.833 & $0.09-34$ & 0.687 \\
\hline$M G M T$ & Methylated $v s$. unmethylated & 0.3 & $0.1-0.6$ & 0.004 & 0.612 & $0.2-1.6$ & 0.327 \\
\hline$I D H 1$ & Mutated vs. wild-type & 0.1 & $0.05-0.04$ & 0.001 & 0.302 & $0.05-1.5$ & 0.156 \\
\hline TP53 & Mutated $v s$. wild-type & 0.8 & $0.3-2.0$ & 0.758 & & & \\
\hline TERT promoter & Mutated vs. wild-type & 1.2 & $0.5-2.8$ & 0.604 & & & \\
\hline $1 \mathrm{p} / 19 \mathrm{q}$ co-deleted & Co-deletion $v s$. no co-deletion & 0.1 & $0.02-1.1$ & 0.069 & & & \\
\hline Radiation & Received $v s$. not received & 26.8 & $3.5-200.7$ & 0.001 & 8.606 & $0.6-115$ & 0.104 \\
\hline
\end{tabular}

Cox proportional hazard model was applied for the statistical analysis. LC3: Light chain 3; IDH: isocitrate dehydrogenase; MGMT: $O^{6}$-methylyguanine-DNA methyltransferase; TP53: tumor protein 53; TERT: telomerase reverse transcriptase.

positive status $(p=0.022)$, HGG $(p=0.004)$ and those who received radiation therapy $(p=0.001)$, whereas cases with MGMT methylation $(p=0.004)$ and IDHI mutated type $(p=0.001)$ had favorable prognosis. However, multivariate analysis revealed that the above parameters were not independent prognostic factors for overall survival (Table IV).

\section{Discussion}

In the current study, expression of autophagy-related proteins in various types of gliomas and their relationship with clinicopathological parameters and clinical outcomes were evaluated. Remarkably, the expression of all three autophagyrelated proteins $\mathrm{LC} 3$, beclin 1 and p62, along with the autophagy status was found to be closely associated with tumor histology and was relatively more frequent in HGG than in LGG. Positivity for LC3, p62 and autophagy was found to be significantly associated with poor prognosis, whereas the expression of beclin 1 was not significantly correlated in determining the overall prognosis as shown in the Kaplan-Meier survival analysis. Additionally, close association between the autophagy-related proteins LC3 and p62 was also seen, suggesting that these proteins may interact with each other and play a significant role in the regulation of autophagy activation. These findings could also be due to the active role of LC3 and p62 during autophagy as they are the structural component of autophagosomes $(16,29,30)$. Beclin 1 is an autophagosome initiation protein and thus this could 

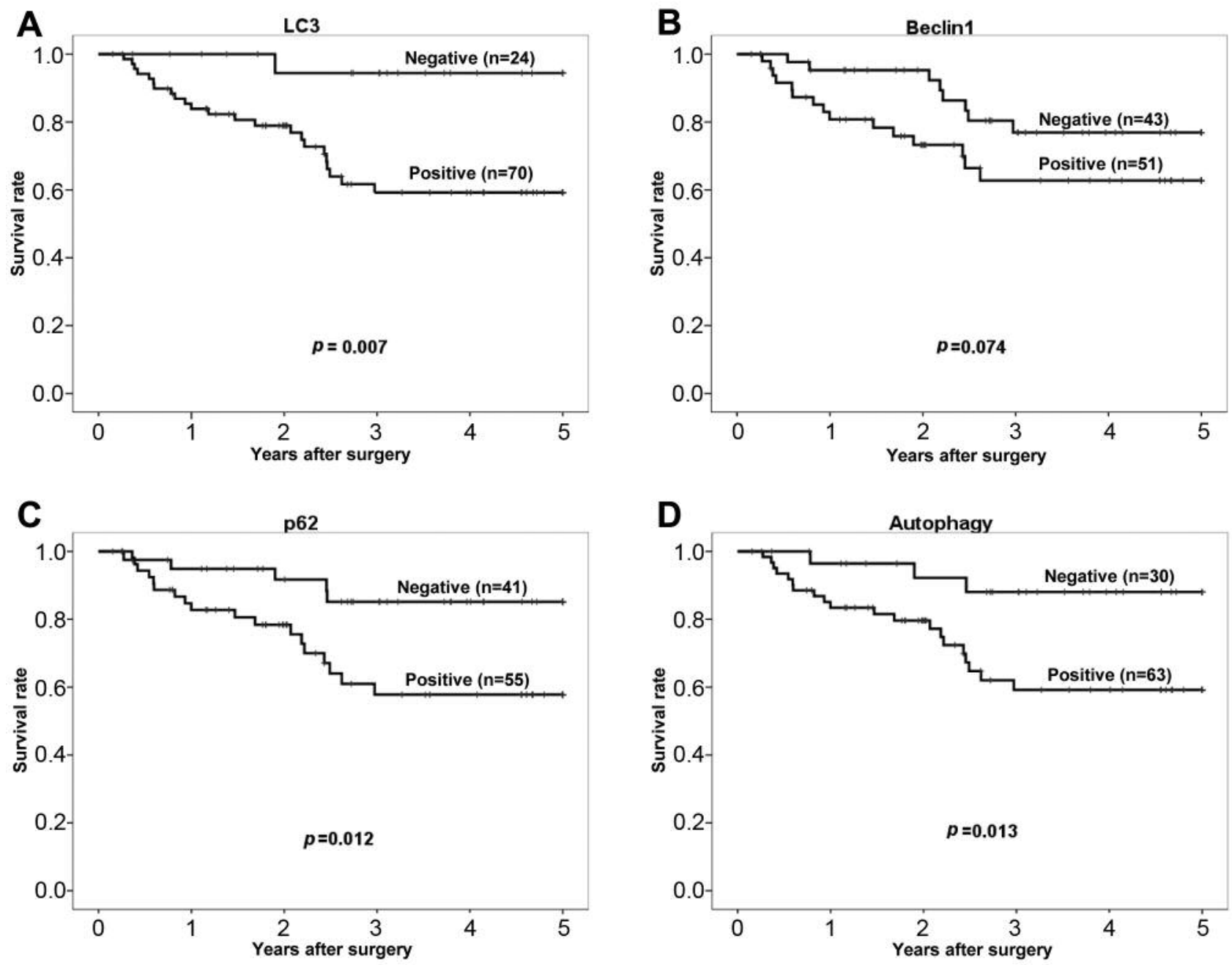

Figure 2. Kaplan-Meier survival curves for the 97 glioma cases according to expression of light chain 3 (LC3), beclin 1 and p62, and autophagy status. Positivity for the expression of LC3 and p62, and autophagy was associated with significantly poorer overall survival. The expression of beclin 1, however, was not significantly correlated with patient survival. The overall survival of patients with autophagy-positive tumors was significantly poorer than that for those with autophagy-negative tumors.

be the reason for the insignificant correlation of beclin 1 with the overall prognosis in our series. High levels of LC3 and p62 have also been reported to be significantly associated with prognosis in patients with HGG, breast cancer and oral cell carcinoma $(31,32)$. Studies have shown beclin 1 expression to be associated with longer survival in patients with colon and esophageal cancer and its low expression has been associated with poor prognosis in hepatocellular carcinoma (32-34). Cytoplasmic protein expression of beclin 1 was found to be reduced in HGG versus LGG, suggesting a loss of gene function (35). One of the possible mechanisms for this is that beclin 1 expression reduces the frequency of additional mutation and limits chromosomal instability (9). Positivity for LC3, beclin 1, p62 and autophagy was also found to be closely associated with radiation therapy but whether radiation induces autophagy or protects cells is still debatable (36).

With the introduction of 2016 WHO classification of tumors of the central nervous system, the molecular identification of gliomas, such as for $M G M T$ methylation, IDH1, TP53 and TERT promoter mutation, and $1 \mathrm{p} / 19 \mathrm{q}$ codeletion, is now a pivotal procedure incorporated into the diagnosis and treatment strategy of gliomas. These molecular markers also assist in predicting the sensitivity of the tumor to chemotherapy and radiation therapy $(37,38)$. Recently, these molecular markers were shown to be useful in predicting the prognosis and treatment response in gliomas (10, 32, 39). However, studies on autophagy and the molecular markers of glioma are limited. 
In our study, we evaluated these molecular markers and investigated their association with autophagy. Individually, there was significant association of LC3 with MGMT methylation and TERT promoter mutation; beclin 1 with IDH1 mutation and 1p/19q co-deletion; and p62 with MGMT methylation, IDHI mutation and $1 \mathrm{p} / 19 \mathrm{q}$ co-deletion. Autophagy status was also significantly associated with MGMT methylation, IDHI mutation and 1p/19q co-deletion, suggesting that there might be a close association between autophagy and MGMT methylation, IDHI mutation and 1p/19q co-deletion. One possible hypothesis linking autophagy mechanisms with $M G M T$ methylation: could be that the presence of methylated $M G M T$ promoter reduces the proficiency to repair DNA damage, ultimately resulting in cancer cell death (apoptosis); autophagy has a unique role in cell death pathways and although autophagy and apoptosis are controlled by multiple signals, they are also thought to cross-regulate each other (39). This could be one possible linkage, however, the crosstalk between autophagy and apoptosis is still controversial and complex (40). Our results also showed a close association between autophagy and $1 \mathrm{p} / 19 \mathrm{q}$ co-deletion and $I D H 1$ mutation. Combined loss of chromosomal arms $1 \mathrm{p}$ and $19 \mathrm{q}$ is associated with improved survival as damaged DNA is unable to be repaired thus eventually leading to cancer cell death or apoptosis. A study showed that mutant IDHI can have profound effect on autophagy but whether $I D H 1$ mutation develops spontaneously or depends on other co-existing genetic alterations is yet to be investigated (41): However, there is paucity of data regarding the association between autophagy and genetic mutations of gliomas in literature and further studies need to be carried out to fully determine its association. Autophagy activity was closely associated with MGMT methylation, IDHI mutation and $1 \mathrm{p} / 19 \mathrm{q}$ co-deletion, making this the first report of such a finding.

The poor response of brain tumors to multi-modality treatment has urged the need to target autophagy as an alternative death pathway. Recently, studies have shown chloroquine, a widely used antimalarial agent, to actively inhibit autophagy (42-44). Thus, autophagy-interfering agents in conjunction with radiation and chemotherapy may prove to be a promising novel treatment strategy for gliomas. Further studies incorporating autophagy markers and molecular alterations are also warranted to determine their putative prognostic or diagnostic importance for gliomas.

In conclusion, autophagy may be associated with the progression of glioma, especially in HGG type. LC3 and p62 significantly correlated with poorer prognosis, suggesting that LC3 and p62 might be considered as useful prognostic factors of gliomas.

\section{Acknowledgements}

The Authors would like to thank Megumi Yoshino (Department of Neurosurgery, Osaka City University Graduate School of Medicine) for her generous technical assistance with sample collection for gene analysis, and Kayo Tubota (Molecular Oncology and
Therapeutics, Osaka City University Graduate School of Medicine) for technical assistance in immunohistochemical staining.

\section{Conflicts of Interest}

No financial or other interest exists that might be construed as a conflict of interest in regard to this study.

\section{Authors' Contributions}

ST and MY designed the study; ST performed the research; TK provided sample collection; TK, TU, YT and KO provided clinical support; ST, MY, YK and MO contributed to staining interpretation; ST wrote the manuscript, and MY critically revised the manuscript and interpretation of the data. All Authors reviewed, edited and approved the final version of the manuscript.

\section{References}

1 Louis DN, Perry A, Reifenberger G, von Deimling A, FigarellaBranger D, Cavenee WK, Ohgaki H, Wiestler OD, Kleihues P and Ellison DW: The 2016 World Health Organization Classification of Tumors of the Central Nervous System: a summary. Acta Neuropathol 131(6): 803-820, 2016. PMID: 27157931. DOI: 10.1007/s00401-016-1545-1.

2 Maher EA, Furnari FB, Bachoo RM, Rowitch DH, Louis DN, Cavenee WK and DePinho RA: Malignant glioma: genetics and biology of a grave matter. Genes Dev 15(11): 1311-1333, 2001. PMID: 11390353. DOI: 10.1101/gad.891601

3 van den Bent MJ, Afra D, de Witte O, Ben Hassel M, Schraub S, Hoang-Xuan K, Malmström PO, Collette L, Piérart M, Mirimanoff R, Karim AB and EORTC Radiotherapy and Brain Tumor Groups and the UK Medical Research Council: Longterm efficacy of early versus delayed radiotherapy for low-grade astrocytoma and oligodendroglioma in adults: the EORTC 22845 randomised trial. Lancet 366(9490): 985-990, 2005. PMID: 16168780. DOI: 10.1016/S0140-6736(05)67070-5

4 Chaichana KL, McGirt MJ, Laterra J, Olivi A and QuiñonesHinojosa A: Recurrence and malignant degeneration after resection of adult hemispheric low-grade gliomas. J Neurosurg 112(1): 10-17, 2010. PMID: 19361270. DOI: 10.3171/ 2008.10.JNS08608

5 Oberheim Bush NA and Chang S: Treatment strategies for lowgrade glioma in adults. J Oncol Pract 12(12): 1235-1241, 2016. PMID: 27943684. DOI: 10.1200/JOP.2016.018622

6 Wen PY and Kesari S: Malignant gliomas in adults. N Engl J Med 359(5): 492-507, 2008. PMID:18669428. DOI: 1056/ NEJMra0708126

7 Giatromanolaki A, Sivridis E, Mitrakas A, Kalamida D, Zois CE, Haider S, Piperidou C, Pappa A, Gatter KC, Harris AL and Koukourakis MI: Autophagy and lysosomal related protein expression patterns in human glioblastoma. Cancer Biol Ther 15(11): 1468-1478, 2014. PMID: 25482944. DOI: 10.4161/ 15384047.2014.955719

8 Kung C, Budina A, Balaburski G, Bergenstock MK and Murphy M: Autophagy in tumor Suppression and cancer therapy. Crit Rev Eukaryot Gene Expr 21(1): 71-100, 2011. PMID: 21967333

9 Mathew R, Kongara S, Beaudoin B, Karp CM, Bray K, Degenhardt K, Chen G, Jin S and White E: Autophagy 
suppresses tumor progression by limiting chromosomal instability. Genes Dev 21(11): 1367-1381, 2007. PMID: 17510285. DOI: $10.1101 / \mathrm{gad} .1545107$

10 Eckel-Passow JE, Lachance DH, Molinaro AM, Walsh KM, Decker PA, Sicotte H, Pekmezci M, Rice T, Kosel ML, Smirnov IV, Sarkar G, Caron AA, Kollmeyer TM, Praska CE, Chada AR, Halder C, Hansen HM, McCoy LS, Bracci PM, Marshall R, Zheng S, Reis GF, Pico AR, O'Neill BP, Buckner JC, Giannini C, HUse JT, Perry A, Tihan T, Berger MS, Chang SM, Prados MD, Wiemels J, Wiencke JK, Wrensch MR and Jenkins RB: Glioma groups based on $1 \mathrm{p} / 19 \mathrm{q}$, IDH, and TERT promoter mutations in tumors. N Engl J Med 372(26): 2499-508, 2015. PMID: 26061753. DOI: 10.1056/NEJMoa1407279

11 Zhang D, Tang B, Xie X, Xiao YF, Yang SM and Zhang JW: The interplay between DNA repair and autophagy in cancer therapy. Cancer Biol Ther 16(7): 1005-1013, 2015. PMID: 25985143. DOI: $10.1080 / 15384047.2015 .1046022$

12 Kimmelman AC: The dynamic nature of autophagy in cancer. Genes Dev 25(19): 1999-2010, 2011. PMID: 21979913. DOI: $10.1101 / \mathrm{gad} .17558811$

13 White E, Karp C, Strohecker AM, Guo Y and Mathew R: Role of autophagy in suppression of inflammation and cancer. Curr Opin Cell Biol 22(2): 212-217, 2010. PMID: 20056400. DOI: 10.1016/j.ceb.2009.12.008

14 Guo JY, Chen H, Mathew R, Fan J, Strohecker AM, KarsliUzunbas G, Kamphorst JJ, Chen G, Lemons JMS, Karantza V, Coller HA, Dipaola RS, Gelinas C, Rabinowitz JD and White E: Activated RAS requires autophagy to maintain oxidative metabolism and tumorigenesis. Genes Dev 25(5): 460-470, 2011. PMID: 21317241. DOI: $10.1101 / \mathrm{gad} .2016311$

15 Mathew R, Karantza-Wadsworth V and White E: Role of autophagy in cancer. Nat Rev Cancer 7(12): 961-967, 2010. PMID: 17972889 . DOI: $10.1038 / \mathrm{nrc} 2254$

16 Yang $\mathrm{Z}$ and Klionsky DJ: An overview of the molecular mechanism of autophagy. Curr Top Microbiol Immunol 335: 132, 2009. PMID: 19802558. DOI: 10.1007/978-3-642-00302-8_1

17 Levine B and Kroemer G: Autophagy in the pathogenesis of disease. Cell 132(1): 27-42, 2008. PMID: 18191218. DOI: 10.1016/j.cell.2007.12.018

18 Mizushima N, Levine B, Cuervo AM and Klionsky DJ: Autophagy fights disease through cellular self-digestion. Nature 451(7182): 1069-1075, 2008. PMID: 18305538. DOI: $10.1038 /$ nature 06639

19 Levine B and Klionsky DJ: Development by self-digestion: Molecular mechanisms and biological functions of autophagy. Dev Cell 6(4): 463-477, 2004. PMID: 15068787

20 Schläfli AM, Berezowska S, Adams O, Langer R and Tschan MP: Reliable LC3 and p62 autophagy marker detection in formalin fixed paraffin embedded human tissue by immunohistochemistry. Eur J Histochem 59(2): 2481, 2015. PMID: 26150155. DOI: $10.4081 /$ ejh.2015.2481

21 Gozuacik D and Kimchi A: Autophagy as a cell death and tumor suppressor mechanism. Oncogene 23(16): 2891-2906, 2004. PMID: 15077152. DOI: 10.038/sj.onc.1207521

22 Shpilka T, Mizushima N: and Elazar Z: Ubiquitin-like proteins and autophagy at a glance. J Cell Sci 125(Pt 10): 2343-2348, 2012. PMID: 22736434. DOI: $10.1242 /$ jcs.093757

23 Klionsky DJ: The molecular machinery of autophagy: unanswered questions. J Cell Sci 118(Pt 1): 7-18, 2005. PMID: 15615779. DOI: $10.1242 /$ jcs.01620
24 Mijaljica D, Nazarko TY, Brumell JH, Huang W, Komatsu M and Prescott M, Simonsen A, Yamamoto A, Zhang H, Klionsky DJ and Devenish RJ: Receptor protein complexes are in control of autophagy. Autophagy 8(11): 1701-1705, 2012. PMID: 22874568. DOI: $10.4161 /$ auto.21332

25 Yue Z, Jin S, Yang C, Levine AJ and Heintz N: Beclin 1, an autophagy gene essential for early embryonic development, is a haploinsufficient tumor suppressor. Proc Natl Acad Sci USA 100(25): 15077-15082, 2003. PMID: 14657337. DOI: 10.1073/ pnas. 2436255100

26 Winardi D, Tsai HP, Chai CY, Chung CL, Loh JK, Chen YH and Hsieh CL: Correlation of altered expression of the autophagy marker LC3B with poor prognosis in astrocytoma. Biomed Res Int 2014: 723176, 2014. PMID: 24900981. DOI: 10.1155/2014/ 723176

27 Puissant A, Fenouille N and Auberger P: When autophagy meets cancer through p62/SQSTM1. Am J Cancer Res 2(4): 397-413, 2012. PMID: 22860231

28 Jiang $\mathrm{T}$ and $\mathrm{Wu} \mathrm{Z}$ : Immunohistochemical assessment of autophagic protein LC3B and p62 levels in glioma patients. Int J Clin Exp Pathol 11(2): 862-868, 2018. www.ijcep.com/ ISSN:1936-2625/IJCEP0065157

29 Shi YH, Ding ZB, Zhou J, Qiu SJ and Fan J: Prognostic significance of Beclin 1-dependent apoptotic activity in hepatocellular carcinoma. Autophagy 5(3): 380-382, 2009. PMID: 19145109.

30 Li BX, Li CY, Peng RQ, Wu XJ, Wang HY, Wan DS, Zhu XF and Zhang XS: The expression of beclin 1 is associated with favourable prognosis in stage IIIB colon cancers. Autophagy 5(3): 303-306, 2009. PMID: 19066461.

31 Chen S, Jiang YZ, Huang L, Zhou RJ, Yu KD, Liu Y and Shao ZM: The residual tumor autophagy marker LC3B serves as a prognostic marker in local advanced breast cancer after neoadjuvant chemotherapy. Clin Cancer Res 19(24): 6853-6862, 2013. PMID: 24141623. DOI: 10.1158/1078-0432.CCR-13-1617

32 Arita H, Yamasaki K, Matsushita Y, Nakamura T, Shimokawa A, Takami H, Tanaka S, Mukasa A, Shirahata M, Shimizu S, Suzuki K, Saito K, Kobayashi K, Higuchi F, Uzuka T, Otani R, Tamura K, Sumita K, Ohno M, Miyakita Y, Kagawa N, Hashimoto N, Hatae R, Yoshimoto K, Shinojima N, Nakamura H, Kanemura Y, Okita Y, Kinoshita M, Ishibashi K, Shofuda T, Kodama Y, Mori K, Tomogane Y, Fukai J, Fujita K, Terakawa Y, Tsuyuguchi N, Moriuchi S, Nonaka M, Suzuki H, Shibuya M, Maehara T, Saito N, Nagane M, Kawahara N, Ueki K, Yoshimine T, Miyaoka E, Nishikawa R, Komori $\mathrm{T}$, Narita $\mathrm{Y}$ and Ichimura $\mathrm{K}$ : A combination of TERT promoter mutation and MGMT methylation status predicts clinically relevant subgroups of newly diagnosed glioblastomas. Acta Neuropathol Commun 4(1): 79, 2016. PMID: 27503138. DOI: 10.1186/s40478-016-0351-2

33 Klionsky DJ, Abdelmohsen K, Abe A, Abedin MJ, Abeliovich $\mathrm{H}$, Acevedo Arozena A, Adachi H, Adams CM, Adams PD, Adeli K, Adhihetty PJ, Adler SG et al: Guidelines for the use and interpretation of assays for monitoring autophagy (3rd edition). Autophagy 12(1): 1-222, 2016. PMID: 26799652. DOI: 10.1080/15548627.2015.1100356.

34 Chen Y, Lu Y, Lu C and Zhang L: Beclin 1 expression is a predictor of clinical outcome in patients with esophageal squamous cell carcinoma and correlated to hypoxia-inducible factor (HIF)-1 $\alpha$ expression. Pathol Oncol Res 15(3): 487-493, 2009. PMID: 19130303. DOI: 10.1007/s12253-008-9143-8 
35 Miracco C, Cosci E, Oliveri G, Luzi P, Pacenti L, Monciatti I, Mannucci S, Nisi MCDE, Toscano M, Malagnino V, Falzarano SM, Pirtoli L and Tosi P: Protein and mRNA expression of autophagy gene beclin 1 in human brain tumours. Int J Oncol 30(2): 429-436, 2007. PMID: 17203225.

36 Zhuang W, Qin Z and Liang Z: The role of autophagy in sensitizing malignant glioma cells to radiation therapy. Acta Biochim Biophys Sin 41(5): 341-351, 2009. PMID: 19430698.

37 Cairncross G, Wang M, Shaw E, Jenkins R, Brachman D, Buckner J, Fink K, Souhami L, Laperriere N, Curran W and Mehta M: Phase III trial of chemoradiotherapy for anaplastic oligodendroglioma: Long-term results of RTOG 9402. J Clin Oncol 31(3): 337-343, 2013. PMID: 23071247. DOI: 10.1200/JCO.2012.43.2674

38 Buckner JC, Shaw EG, Pugh SL, Chakravarti A, Gilbert MR, Barger GR, Coons S, Ricci P, Bullard D, Brown PD, Stelzer K, Brachman D, Suh JH, Schultz CJ, Bahary JP, Fisher BJ, Kim H, Murtha AD, Bell EH, Won M, Mehta MP and Curran WJ, Jr: Radiation plus procarbazine, CCNU, and vincristine in lowgrade glioma. N Engl J Med 374(14): 1344-1355, 2016. PMID: 27050206. DOI: 10.1053/NEJMoa1500925

39 Lee Y, Koh J, Kim S, Won JK, Park CK, Choi SH and Park SH: The frequency and prognostic effect of TERT promoter mutation in diffuse gliomas. Acta Neuropathol Commun 5(1): 62, 2017. PMID: 28851427. DOI: 10.1186/s40478-017-0465-1

40 Mariño G, Niso-santano M, Baehrecke EH and Kroemer G: Selfconsumption: the interplay of autophagy and apoptosis. Nat Rev Mol Cell Biol 15(2): 81-94, 2014. PMID: 24401948. DOI: $10.1038 / \mathrm{nrm} 3735$

41 Doherty J and Baehrecke EH: Life, death and autophagy. Nat Cell Biol 20(10): 1110-1117, 2018. PMID: 30224761. DOI: 10.1038/s41556-018-0201-5
42 Gilbert MR, Liu Y, Neltner J, Pu H, Morris A, Sunkara M, Pittman T, Kyprianou $\mathrm{N}$ and Horbinski $\mathrm{C}$ : Autophagy and oxidative stress in gliomas with IDH1 mutations. Acta Neuropathol 127(2): 221-233, 2014. PMID: 24150401. DOI: 10.1007/s00401-013-1194-6

43 Redmann M, Benavides GA, Berryhill TF, Wani WY, Ouyang X, Johnson MS, Ravi S and Barnes S, Darley-Usmar VM and Zhang J: Inhibition of autophagy with bafilomycin and chloroquine decreases mitochondrial quality and bioenergetic function in primary neurons. Redox Biol 11: 73-81, 2017. PMID: 27889640. DOI: 10.1016/j.redox.2016.11.004

44 Mauthe M, Orhon I, Rocchi C, Zhou X, Luhr M, Hijlkema K, Coppes RP, Engedal N, Mari M and Reggiori F: Chloroquine inhibits autophagic flux by decreasing autophagosome-lysosome fusion. Autophagy 14(8): 1435-1455, 2018. PMID: 29940786. DOI: $10.1080 / 15548627.2018 .1474314$

45 Jia B, Xue Y, Yan X, Li J, Wu Y, Guo R, Zhang J, Zhang L, Li Y, Liu Y and Sun L: Autophagy inhibitor chloroquine induces apoptosis of cholangiocarcinoma cells via endoplasmic reticulum stress. Oncol Lett 16(3): 3509-3516, 2018. PMID: 30127955. DOI: $10.3892 / \mathrm{ol} .2018 .9131$
Received January 22, 2019

Revised February 7, 2019 Accepted February 14, 2019 